\title{
O LUGAR DOS MEDIADORES DE LEITURA
}

Rita de Cassia Brêda M. Lima ${ }^{1}$

Nas últimas décadas, a figura do mediador vem ocupando espaços significativos quando o assunto é a formação de leitores. Assumem papel de mediação não apenas os professores ou os bibliotecários, mas a família, os escritores, os livreiros, os padres ou pastores, e também pessoas do convívio cotidiano, como os amigos que se dispõem a ofertar o banquete da leitura, dentre tantos outros.

Reconhecendo a importância da formação de leitores é que buscamos compreender, durante a pesquisa de doutorado ${ }^{2}$, qual o papel do mediador na formação leitora dos alunos da rede estadual de ensino de Feira de Santana na Bahia. A pesquisa, de abordagem qualitativa, utilizou como instrumentos geradores de dados: diário de campo, grupo de discussão e entrevistas narrativas.

A leitura como afirma Yunes (2011) é "condição de aprendizagem" e, sendo assim, "Leitura não é só letramento, mas visão de mundo. Quem lê pensa. E quem pensa não cala. É urgente, portanto, incentivar a leitura, não só em sua dimensão educacional, mas em sua dimensão social e cultural" (p. 29) e o mediador passa a assumir a tarefa de alguém que acolhe, que oferece, que propicia o encontro do leitor com os materiais culturais diversos, ou é quem "prepara a cena para a presença do texto literário" como defende Gonçalves (2014).

É papel do mediador de leitura, principalmente aquele que atua na biblioteca escolar, divulgar, indicar, circular, apresentar o acervo disponível, mas, essa não é uma ação mecânica, destituída de intenções e objetivos, cabe a este não apenas conhecer a localização dos livros nas estantes, mas ter com os livros uma relação de intimidade, de encantamento ou, como defende Gregório Filho (1998), "ter de cor” um repertório literário. Para este autor, ter de cor as histórias é fazê-las morar dentro de nós e, assim, por estar no coração, saem de cor - de coração.

O desafio da escola e da biblioteca escolar, mais precisamente, tem aumentado nas últimas décadas. Não há dúvida que é papel da escola, em todos os seus espaços e práticas formativas, oportunizar aos alunos o encontro com o conhecimento, o domínio de saberes e a compreensão plena da realidade. Mas, essa não tem sido uma tarefa fácil. São inúmeras as dificuldades que, nas últimas décadas, a instituição escolar vem se deparando. Em boa parte das escolas estaduais de Feira de Santana o problema enfrentado pelos professores não é mais a ausência de equipamentos tecnológicos (data show; DVD, som, TV), de livros didáticos, paradidáticos, literários e de condições básicas para o processo de ensino-aprendizagem. $\mathrm{Na}$ atualidade, a maioria das escolas dispõe dessas condições básicas, entretanto, o que tem agravado sensivelmente as rotinas das bibliotecas escolares é a falta de funcionário exclusivamente para assumir tal responsabilidade. E, as escolas que conseguem fazer remanejamento de função dentre os funcionários e coloca um (ou mais) para atender e mantêla aberta ao público, se depara com a falta de formação específica para lidar com a organização e dinamização do acervo e as demandas inerentes ao cotidiano de uma biblioteca.

Sobre a dinamização de acervo, dialogo com Besnosik (2015), quando afirma que ao "Mexer na memória, buscando esse acervo pessoal, nos faz pensar que nós todos possuímos uma história como leitores e que, na prática, somos dinamizadores de acervos à medida que fazemos, de certa forma, circular essas nossas leituras" (2015, p. 120). Portanto, para os

\footnotetext{
${ }^{1}$ Professora Assistente do Departamento de Educação - Universidade Estadual de Feira de Santana - UEFS. E-mail: rbredalima@yahoo.com.br.

${ }^{2}$ Tese defendida no Programa de Pós-graduação em Educação na Faculdade de Educação da Universidade Federal da Bahia-UFBA “Bibliotecas Escolares: realidades, práticas e desafios para formar leitores”, 2017. Repositório da UFBA.
} 
responsáveis por uma biblioteca escolar assumirem o papel de mediador de leitura, suas atribuições não se resumem em controlar o empréstimo dos livros e manter o acervo organizado nas estantes, requer outras habilidades e envolvimentos com os livros e com os leitores, a fim de seduzi-los para esse universo.

Essa demanda foi manifestada durante a pesquisa quando os leitores afirmaram que os funcionários da biblioteca precisam ser acolhedores. Para Ruth ${ }^{3}$, aluna e usuária assídua da biblioteca escolar, é preciso:

além de ter livros bons, eu acho que não vale a pena só a gente ter livros bons na biblioteca, a gente precisa de pessoas boas para trabalharem, por exemplo, você chega e não está achando o livro que você procura, a pessoa vai lá e ajuda [...]. Tinha um funcionário que ele fazia isso, porque quando não tinha o livro que eu queria, ele falava eu tenho tal livro que tem esse assunto, tem esse tipo literário que fala sobre isso e ele me emprestava até dele mesmo. Se uma pessoa está ali para fazer o trabalho, precisa fazer bem feito e eu acho que ele fazia um trabalho bem feito. (Entrevista, 28/02/2016) (grifo nosso)

Para atuar na biblioteca escolar cumprindo efetivamente o papel de mediador, é importante que este seja em primeiro lugar um leitor. Sendo leitor, é inevitável conhecer as obras, os autores disponíveis na BE e assim transitar por entre saberes, conteúdos e indicações bibliográficas tão necessárias no processo de orientação e de ajuda aos alunos leitores.

Há consenso tanto entre os autores quanto no meio educacional que só desperta o gosto e o encantamento pela leitura, aqueles que também são encantados por ela. Assim, é preciso investir na formação de mediadores de leitura tanto para atuar nos espaços formais como escola e biblioteca como em espaços alternativos ou não formais, pois sabemos que a responsabilidade por formar o gosto pela leitura não é de exclusividade apenas da escola.

Michele Petit em sua obra $A$ arte de ler (2009) nos instiga a pensar:

Se o adulto impõe à criança o comportamento que ela deve ter, o bom jeito de ler, se ela se submete passivamente à autoridade de um texto, encarando-o como algo que lhe é imposto e sobre o que ela deve prestar contas, são poucas as chances de o livro entrar na experiência dela, na sua voz, no seu pensamento. (PETIT, 2009, p. 47-48)

Sobre essa mesma questão Pennac (1993, p. 13) na sua obra Como um romance já nos alertava que "O verbo ler não suporta imperativo", portanto, não será pela via da imposição, do simples conselho de que "a leitura é importante" que conseguiremos tornar nossos alunos leitores. Sabemos que a prática da leitura e, consequentemente, os gostos e os modos de ler são aprendizados socialmente construídos, e, mais do que isso, é importante ressaltar que nem sempre aconteceu desse modo. Ao longo da história da leitura muitas foram as circunstâncias em que a leitura era censurada, proibida (VILLALTA, 2005; ABREU, 2003; 2005) ou considerada ato subversivo (PENNAC, 1993), e só muito recentemente é que passamos a tratála como uma prática e um aprendizado necessários para uma melhor inserção sociocultural. Afinal, conforme nos rememora Abreu no ensaio Diferentes formas de ler ${ }^{4}$ :

\footnotetext{
${ }^{3}$ Nome fictício, sugerido pela colaboradora da pesquisa.

${ }^{4}$ Texto originalmente apresentado na Mesa-redonda - Práticas de Leituras: história e modalidades, no XXIV Congresso Brasileiro de Ciências da Comunicação, Intercom, Campo Grande, 2001.
} 
É relativamente recente também a ideia de que o bom leitor é o que lê muitos e variados textos. Durante séculos a quantidade de impressos disponível era pequena, seu preço, elevado, e o livro, muitas vezes, sacralizado - mesmo que não tratasse de tema religioso. $\mathrm{O}$ bom leitor era aquele que lia pouco, relia com frequência e meditava muito sobre os escritos. Ler muito poderia ser visto como um problema - até mesmo para a saúde. (ABREU, 2001, p. 01)

Compreendendo as múltiplas e complexas formas e defesas pelo ato de ler e, consequentemente, pela necessária apropriação de um modus operandi de leitura que atenda aos moldes e exigências atuais, não podemos prescindir de uma análise cuidadosa sobre os diversos contextos sociais que nossos alunos co-habitam pois, lidamos diariamente com inúmeras "interdições culturais" (PETIT, 2009) e assim, novamente a escola e a biblioteca escolar são convocadas e, porque não dizer, requisitadas, a assumirem o protagonismo e a responsabilidade de realizar, em seus múltiplos espaços, ações culturais que corroborem para compartilhamentos de encontros e experiências literárias e de outras práticas culturais.

A pesquisa realizada em escolas da rede estadual de ensino do município de Feira de Santana, na Bahia, trouxe à tona percepções e descobertas acerca das condições de funcionamento das $\mathrm{BE}$, modos de interagir e de mediar a formação de leitores. Dentre os achados, revelou presenças tímidas de mediadores de leitura nas escolas pesquisadas. Seja pelas recorrentes falas que denotavam a pouca inserção ou mesmo ausências de marcas ou referências dos professores para a constituição leitora dos alunos, seja pelas parcas ações articuladas entre as disciplinas e o acervo disponível na BE. Portanto, o cenário mais uma vez aponta a pujante necessidade de investimentos em políticas efetivas de formação de mediadores de leitura em diversos espaços e de construção de uma representação da biblioteca como lugar de circulação e imersão nas diversas práticas culturais de leitura.

\section{Referências}

ABREU, Márcia. Os caminhos dos livros. Campinas, SP: Mercado das Letras, Associação de Leitura do Brasil (ALB); São Paulo, SP: Fapesp; 2003.

ABREU, Márcia. Em busca do leitor: estudo dos registros de leitura de censores. In.: ABREU, Márcia; SCHAPOCHNIK, Nelson (Org.) Cultura letrada no Brasil: objetos e práticas. Campinas, SP: Mercado das Letras, Associação de Leitura do Brasil (ALB); São Paulo, SP: Fapesp; 2005.

BESNOSIK, Maria Helena da Rocha. Dinamização de acervos: de que acervos falamos? Leitura em Revista, UNESCO Cátedra de Leitura - PUC - RIO, n. 8, mai. 2015. ISSN 2179-2801. Disponível em: <http://iiler.puc-rio.br/wp-content/uploads/2016/01/LER8ed. pdf>. Acesso em: 03/02/2016

GONÇALVES, Luciana Sacramento Moreno. Os jovens em círculos de leitura literária: uma proposta para espaços alternativos. PUC/RS. Programa de Pós-graduação em Letras. Porto Alegre, 2014 (Tese de doutorado).

GREGÓRIO FILHO, Francisco. Guardados do coração - memorial para contadores de histórias. Rio de Janeiro: Amais Livraria e Editora Ltda, 1998.

PENNAC, Daniel. Como um romance. Rio de Janeiro: Rocco, 1993. 
PETIT, Michèle. A arte de ler: ou como resistir à adversidade. São Paulo: Editora 34, 2009.

PETIT, Michèle. Os jovens e a leitura - uma nova perspectiva. São Paulo: Ed. 34, 2009.

VILLALTA, Luiz Carlos. A censura, a circulação e a posse de romances na América Portuguesa (1722-1822). In: ABREU, Márcia; SCHAPOCHNIK, Nelson (Org.) Cultura letrada no Brasil: objetos e práticas. Campinas, SP: Mercado das Letras, Associação de Leitura do Brasil (ALB); São Paulo, SP: Fapesp; 2005.

YUNES, Eliana. Leitores a caminho: formando agentes de leitura. PUC-Rio, 2011. 